\title{
COERÊNCIA E DEFESA DA DEMOCRACIA: LAUDATIO PARA CARLOS MARÍA CÁRCOVA ${ }^{1}$
}

Jacinto Nelson de Miranda Coutinho ${ }^{2}$

Como citar este documento / How to cite this document (informe a data atual de acesso / inform the current date of access):

COUTINHO, Jacinto Nelson de Miranda. Coerência e defesa da democracia: laudatio para Carlos María Cárcova. Revista da Faculdade de Direito UFPR, Curitiba, PR, Brasil, v. 64, n. 2, p. 205-209, maio/ago. 2019. ISSN $2236-7284$. Disponível em: https://revistas.ufpr.br/direito/article/view/68280. Acesso em: 31 ago. $2019 . \quad$ DOI: http://dx.doi.org/10.5380/rfdufpr.v64i2.68280.

A outorga do título de doutor honoris causa, o mais importante dos títulos que concede a Universidade Federal do Paraná às pessoas que se destacam por seu prestígio social ou reconhecida contribuição científica, intelectual, acadêmica, cultural ou artística, ao Professor Doutor Carlos María Cárcova, por várias razões é importante, mas, quem sabe, é o reconhecimento de que esta UFPR não está de costas para a América Latina e, assim, reconhece seus filhos pela importância que têm no mundo todo. Isso, nos dias atuais de "pensamento único”, é um sinal de grandeza.

Carlos María Cárcova é portenho, mas viveu durante sua primeira formação, por razões familiares, sobretudo entre estadas em Buenos Aires e General Roca, na Província de Rio Negro. Isso lhe deu um conhecimento de uma Argentina que não é tão só o Distrito Federal e lhe marcou, por certo, uma postura de reconhecimento pelo diferente.

No âmbito universitário formou-se em Direito pela prestigiada Universidad de Buenos Aires - UBA, na qual se doutorou e fez carreira, atingindo o topo dela ao se tornar Professor Titular Ordinário de Filosofia do Direito na Facultad de Filosofía y Letras; e Professor Titular Ordinário de Teoria Geral e Filosofia do Direito na Faculdade de Direito. Foi professor, além da UBA, em várias Universidades da Argentina (UNR - Universidad Nacional de Rosario, UNL - Universidad Nacional del Litoral, UNMdP - Universidad Nacional de Mar del Plata, Universidad Nacional del Comahue), assim como em várias estrangeiras, das quais há de se destacar o período em que lecionou no

\footnotetext{
${ }^{1}$ Laudatio apresentada na sessão solene do Conselho Universitário da UFPR - Universidade Federal do Paraná -, no Salão Nobre da Faculdade de Direito, por ocasião da outorga do título de doutor honoris causa ao Professor Doutor Carlos María Cárcova, em 17 de junho de 2019.

2 Professor Titular de Direito Processual Penal da Universidade Federal do Paraná, aposentado. Professor do Programa de Pós-Graduação em Ciências Criminais da PUCRS. Professor do Programa de Pós-Graduação em Direito da Faculdade Damas, Recife. Especialista em Filosofia do Direito (PUCPR), Mestre (UFPR) e Doutor (Universidade de Roma "La Sapienza”) em Direito. Presidente de Honra do Observatório da Mentalidade Inquisitória. Advogado. Membro da Comissão de Juristas do Senado Federal que elaborou o Anteprojeto de Reforma Global do CPP, hoje Projeto 156/2009PLS.
} 
Programa de Pós-graduação em Direito, nesta UFPR.

Sua produção é imensa e ganhou mundo. Nela se destacam obras como La idea de “ideología” en la Teoría Pura del Derecho (Buenos Aires, Ed. Cooperadora, 1973); Materiales para una teoría crítica del Derecho (Buenos Aires, Abeledo Perrot, 1991); Teorías jurídicas alternativas (Buenos Aires, CEAL, 1994); Derecho y transición democrática (Vitoria, Oñati Proceedings, 1995); Derecho, política y magistratura (Buenos Aires, Biblos, 1996); La opacidad del derecho (Madrid, Trotta, 1998); Las teorías jurídicas post positivistas (Buenos Aires, Lexis Nexis, 2007), para anotar somente as que têm o autor da presente. No Brasil, tem pelo menos quatro livros traduzidos: Direito, política e magistratura (1996); A opacidade do direito (1998), O mundo real: socialismo na era pósneoliberal (2008) e As teorias jurídicas pós-positivistas (2016). A quantidade de ensaios e artigos que tem publicados em revistas especializadas é imensa e não cabe em uma Laudatio que tem espaço e tempo limitados.

Cárcova é Investigador Classe I na Universidad de Buenos Aires; dirigiu por longo período o Instituto de Investigaciones Jurídicas “Ambrosio L. Gioja”, na UBA, na qual é Professor Emérito; dentre outros tantos cargos e funções que exerceu.

Na vida privada é advogado e integrou o Consejo de la Magistratura de la Ciudad Autónoma de Buenos Aires (1998/2002).

Tem duas filhas, do primeiro casamento - Jorgelina e María Dolores (Lola); e tem duas netas, filhas de Lola: Gala e Mora. Todas elas, de certa forma, formam sua razão de viver, junto com a grande Professora Alicia Enriqueta Carmen Ruiz, a quem, apesar da dureza do castellano, conseguiu dizer palavras tão doces de reconhecimento e amor no Prólogo do seu livro maior, La opacidad del derecho, sua tese de cátedra:

Por fin, la ayuda fundamental la recibí de Alicia E. C. Ruiz, con quien comparto la cátedra, la docencia, la investigación y mi vida desde hace muchos años. Ella leyó el manuscrito, paso a paso, mientras se iba gestando y fue una crítica tan inteligente como implacable, tan minuciosa como irreductible. Tales cualidades, unidas a su paciencia y comprensión, fueron definitivamente inestimables y me permitieron exponer mis ideas - cualesquiera que fuera su mérito - de manera muy clara y precisa. Obviamente, también le estoy muy agradecido. ${ }^{3}$

Cárcova, quem sabe por sua formação e por seus pais, sempre foi muito duro consigo mesmo, o que nunca atrapalhou seu relacionamento com seus alunos, em que pese a seriedade que sempre conduziu seu magistério. Dele restaram muitos professores de qualidade, dos quais, tão só para lembrar, destacam-se os Professores Doutores Jorge Eduardo Douglas Price (da Universidad Nacional del Comahue) e Diego Duquelski (Universidad de Buenos Aires).

\footnotetext{
${ }^{3}$ CÁRCOVA, Carlos María. La opacidade del derecho. Madrid: Trotta, 1998, Prólogo, p. 15.
} 
Sua marca, porém, como corifeu da Escola Crítica de Buenos Aires, é a vinculação política com a defesa da democracia e dos direitos humanos, sobretudo dos menos favorecidos. Contestador e crítico, teve embates históricos na sua luta contra o arbítrio, nunca se curvando aos regimes autoritários. Isso lhe rendeu um exílio forçado em 1974, quando veio ao Brasil junto com tantos outros professores incompatibilizados com o regime militar que se instaurara na Argentina, ao qual nunca cedeu. Sobre seu lugar nesses episódios, com reflexos dentro da universidade, melhor que ninguém tratou Juan-Ramón Capella, excepcional catedrático de Barcelona, na Presentación espanhola do seu La opacidade del derecho:

\begin{abstract}
Hay, además, una forma sibilina de colaborar con lo ilegítimo que durante un dilatado período cobró carta de naturaleza a orillas del Río de la Plata. Es el silencio. Uno de esos delitos "de comisión por omisión” que bien conocen los penalistas. Como escribía Carlos Cossio en enero de 1972, en carta personal a quien esto escribe, "En la Facultad de Derecho de Buenos Aires se da la aberración de que en algunas de sus cátedras de Filosofía del Derecho se enseña exclusivamente Lógica simbólica para no chocar con los valores oficialmente dominantes”.// Cuando se desencadenó en la Argentina la represión militar exterminista, a partir de 1974, los cultivadores de la disciplina intelectual que debía ser la consciencia crítica del derecho y del poder ya estaban hechos a la práctica de mirar para otro lado. En las cátedras de filosofía del derecho se siguió enseñando análisis formal, y recibiendo a poco cuidadosos estudiosos extranjeros, mientras los estudiantes, nada formalmente, desaparecían...// Cumplo con el mayor placer el encargo de presentar al público español, por otra parte innecesariamente, este libro de Carlos Cárcova, uno de los profesores que, junto a Enrique Marí, Alicia Ruiz y Ricardo Entelman entre otros, abandonaran la Universidad de Buenos Aires en 1974 como protesta contra la intervención decretada por la presidenta Isabel Martínez. No hay en este caso, pues, ni silencio, ni disfraz, ni colaboración con lo innombrable, sino enfrentamiento político y combate intelectual. ${ }^{4}$
\end{abstract}

Sua obra mais destacada é La opacidad del derecho, como precitado. Dela seria necessário falar um pouco mais, mas, quem sabe, bastaria o alerta que fizeram os grandes professores André Karam Trindade e Alexandre Morais da Rosa em texto elucidativo do Conjur:

Todavia, se a opacidade do Direito é uma característica cada vez mais presente na sociedade
contemporânea, este fenômeno não pode ser estendido aos “operadores do Direito”. Para eles,
não apenas o conhecimento da lei - mais especificamente, da lei constitucional -, mas
também sua vinculação a ela, são impositivos. Este é, aliás, um dos pilares do Estado
Democrático de Direito.// Por isto, a noção de opacidade precisa ser apreendida pelo senso
comum teórico brasileiro, evitando-se, com isso, a responsabilidade praticamente objetiva de
boa parcela da comunidade brasileira, ainda incapaz de compreender a complexidade criada
pelo sistema jurídico brasileiro, de maneira que o estudo da obra de Carlos María Cárcova
pode ser um sendero ${ }^{5}$.

Por outro lado, para ilustrar o imenso domínio que Cárcova sempre teve do mundo em que vive e como sua visão se expande para o futuro, é salutar observar uma das respostas que dá ao

\footnotetext{
${ }^{4}$ CAPELLA, Juan Ramón. La opacidade del derecho. Madrid: Trotta, 1998, Presentación, p.11.

${ }^{5}$ TRINDADE, André Karam; ROSA, Alexandre Morais. Opacidade do Direito ainda é conceito mal compreendido. In: Consultor Jurídico, Diário de Classe. Disponível em: <https://bit.ly/2YzBv37>. Acesso em: 15 jun. 2019.
} 
jornalista Eduardo Raíces, em entrevista que concede quando assume, em 2002, a direção do Instituto de Investigaciones Jurídicas “Ambrosio L. Gioja”, na UBA, sem dúvida o mais importante da Argentina:

Quiero preguntarle, en primer lugar, acerca de sus expectativas al asumir el cargo de Director del Instituto de Investigaciones Ambrosio L. Gioja.

"No son expectativas personales, mas bien son expectativas institucionales. Me parece que la investigación jurídica y social puede tener un papel importante, debe tenerlo, en el diagnóstico de la situación de crisis tan complejas, tan profunda, tan agónica, que caracteriza la situación de nuestro país en esta hora histórica. A diferencia de otros momentos, esta parece ser una crisis, no sólo de una insidiosidad casi inédita, sino también una crisis que abarca absolutamente todos los niveles de la vida social, una crisis que tiene dimensiones éticas, pero también dimensiones institucionales y políticas, económicas, societales, culturales. No quiero abundar en adjetivos, pero realmente parece ser que todos los ámbitos de intercambios y interacción humana están afectados por el signo de la crisis, y, siendo ello así, quienes, de alguna manera, hemos dedicado buena parte de nuestra vida a estudio del modo en que los seres humanos pueden vivir civilizadamente en sociedad a través de pautar sus conductas sobre la base de normas, generadas por mecanismos de participación democrática y legitimidad popular, deberíamos hacer al menos un esfuerzo de diagnóstico. Porque, se tuviéramos alguna posibilidad de comprender qué razones han generado estas situaciones, qué causas nos han sobredeterminado para encontrarnos enfrentando este estado de cosas, esto sería el primer paso ineludible, imprescindible, para comenzar a pensar en estrategias de superación. Sin diagnóstico, no hay posibilidad de políticas alternativas. En los intersticios de todos estos problemas, estamos los hombres de Derecho, los que nos dedicamos a la investigación social, y me parece que el Instituto puede cumplir un papel fundamental. [...]”6.

Em tempos de uma crise aguda como a que se vive hoje, é necessário ter equilíbrio, algo que

tem faltado à gente de esquerda, que se encontra sem alternativas para oferecer contra um neoliberalismo que se fez epistemologia e anda a desgraçar o mundo. Para tal equilíbrio Cárcova já alertava, em 1991, em conferência história no $1^{\circ}$ Congresso de Direito Alternativo, realizado em Florianópolis, no qual dissertou “Acerca de las relaciones entre marxismo y derecho”, mais tarde publicado no livro Teorías jurídicas alternativas: escritos sobre derecho y política:

Ahora bien, como señalara Althusser, la ideologia no es sólo desconocimiento, es también
reconocimiento; elición, pero también alusión. Por eso, por un lado oculta, pero por el otro
fija el lugar de lo que oculta, constituye el lugar de lo que opaca. Así, cuando el derecho nos
promete igualdad, no sólo nos escamotea la percepción de nuestra desigualdad real, también
legitima nuestro reclamo por la igualdad. De tal suerte que el carácter ideológico del derecho
tiene un doble papel, por una parte reconduce las relaciones de poder pero, por la otra, al
legitimar el reclamo, posibilita la reformulación y la transformación progresiva de las
relaciones de poder.// Y, por último, este aspecto el que concierne a las relaciones de poder
un aspecto que en las teorías tradicionales resulta siempre ignorado. Si el poder es un
instrumento, es una cosa que uno tiene y que otros no tienen, lo único que se pode hacer
(como pensaba Lenin) es apoderarse del instrumento del cual carecemos. Es decir si la
burguesía está encerrada en su fortaleza, lo que hay que hacer es tomar la fortaleza. Hacer la
revolución, es tomar la fortaleza, asaltar la Bastilla, ocupar el Palacio de Invierno. La idea de

${ }^{6}$ CÁRCOVA, Carlos María. Entrevista al Dr. Carlos María Cárcova. Por Eduardo Raíces, quando Carlos María Cárcova assumiu a direção do Instituto de Investigaciones Ambrosio Luis Gioja, na Faculta de Derecho da Universidad de Buenos Aires. Disponível em: <https://bit.ly/2YhstIF>. Acesso em: 15 jun. 2019. 
Gramsci, de Althusser y de otros teóricos, en cambio, es distinta. El poder no se piensa como instrumento sino como una relación. Al interior de esta relación existe de manera gravitante, tanto el dominador como el dominado, y lo único que no puede hacer el dominador con el dominado es abatirlo, porque se termina la dominación; lo único que no puede hacer el dominador con el dominado es suprimirlo, porque se termina la relación de poder, se termina su poder. Por lo tanto necesita negociar y reformular permanentemente esa relación, la que juega en un sentido progresivo o en un sentido conservatista y retardatario, de acuerdo a la forma en que históricamente ella se materializa, al interior de una formación social determinada ${ }^{7}$.

Faz-se tempo de terminar. Estaria no gosto fazê-lo com uma passagem história do Professor

Doutor Carlos María Cárcova na Aula Magna de abertura do ano acadêmico de 2005, nesta UFPR:

Si fuéramos capaces de entender los cambio y las transformaciones epocales, para ponerlos al servicio de la emancipación humana, por modesto que haya sido nuestro aporte, habríamos cumplido con la responsabilidad moral que nos impone nuestra condición de mujeres y hombres de derecho. O quizás, más simple y modestamente, nuestra mera condición de seres humanos ${ }^{8}$.

A este grande cidadão do mundo, Carlos María Cárcova, professor de todos nós, a Universidade Federal do Paraná se enche de honra por lhe entregar o título de doutor honoris causa.

Pois que assim seja.

Vida longa ao estimado Professor Doutor Carlos María Cárcova.

Vida longa ao ensino público e gratuito.

Vida longa à Universidade Federal do Paraná.

${ }^{7}$ CÁRCOVA, Carlos María. Acerca de las relaciones entre marxismo y Derecho. In: Teorías jurídicas alternativas: escritos sobre Derecho y Política. Buenos Aires: Centro Editor de América Latina, 1993, p. 84-85.

${ }^{8}$ CÁRCOVA, Carlos María. Discurso inaugural: Derecho y subjetividade. Aula Magna da Faculdade de Direito da UFPR, Curitiba, 2005. 